\title{
Spinoza, Hegel, Deleuze y el problema de la inmanencia
}

\author{
Luis H. Cuevas ${ }^{1}$ \\ Universidad Iberoamericana (México)
}

Recibido: mayo 5 de 2016. Revisado: mayo 10 de 2016. Aceptado: mayo 20 de 2016

Referencia formato APA: Cuevas, L. H (2016). Spinoza, Hegel, Deleuze y el problema de la inmanencia. Rev. Guillermo de Ockham, 14(2), 33-41. doi: http://dx.doi.org/10.21500/22563202.2422

\section{Resumen}

Inscrito en el problema de la inmanencia, el artículo expone los móviles por los cuales Deleuze afirma que Hegel traiciona el movimiento del pensar inmanente. Esto al descubrir en el pensamiento hegeliano un limitado spinozismo que al esbozar una falsa dramatización del devenir, termina por asentar bulbos de trascendencia. Lo anterior se lleva a cabo apoyándonos en la manera como el hegelianismo fue recibido en Francia en el siglo XX, recepción que a partir de la lectura de Judith Butler se afianza en el problema del deseo que halla como una de sus primeras expresiones los cursos que Alexandre Kojève dictó en la École Pratique des Hautes Études.

Palabras clave: Inmanencia, deseo, vitalismo, pensamiento abstracto, negatividad

\section{Spinoza, Hegel, Deleuze and the problem of immanence}

\section{Abstract}

Immersed in the problem of immanence, the paper expresses why Deleuze affirms that Hegel betrays the movement of the immanent thought. For Deleuze, the Hegelian thought embraces a limited Spinozism, these at outlining a false dramatization of becoming that ends up in the creation of bulbs of transcendence. This idea relies on the way in which Hegelianism was received in France in the twentieth century. Reception that from the point of view of Judith Butler is rooted in the problem of desire. Problem that at the same time finds one of its first expressions in France in the École Pratique des Hautes Études at the courses of Alexandre Kojève.

Keywords: Immanence, desire, vitality, abstract thinking, negativity

1. Doctor en Filosofía por la Universidad Nacional Autónoma de México (UNAM). Actualmente hace una estancia postdoctoral en la Universidad Iberoamericana (UIA) con un proyecto abocado a indagar la ontología histórica en el pensamiento de Gilles Deleuze y Félix Guattari. Correo electrónico: luishcuevas@me.com 


\section{Spinoza, Hegel, Deleuze e o problema da imanência}

\section{Resumo}

Inscrito no problema da imanência, o artigo expõe os moveis pôr os cuais Deleuze diz que Hegel trai o movimento do pensamento imanente. Esto ao descobrir no pensamento hegeliano um limitado spinozismo que ao esboçar uma falsa dramatização do devenir, acaba pôr estabelecer bulbos de transcendencia. $\mathrm{O}$ anterior é realizado inclinando-se na maneira como o hegelianismo foi recebido em Francia no século XX, recepção que a partir da leitura de Judith Butler se instala no problema do desejo que encontra como uma de suas primeiras expressóes dos cursos que Alexandre Kojève emitiu na Ecole Pratique des Hautes Etudes.

Palavras-chave: Imanência, desejo, vitalismo, pensamento abstrato, negatividade

\section{Introducción}

Alumbrados por una luz de matiz singular, es factible percibir a Hegel y a Deleuze como dos pensadores que extienden y proyectan la problemática inmanentista. Por un lado, es famosa la fórmula lapidaria que Hölderlin inscribió en el Álbum de Hegel durante su estancia en el Stift: "Profesión de fe: en kai pan" (D'Hondt, 2013, p. 28). Mientras que, por otro lado, en la clase dictada por Deleuze el 24 de marzo de 1981, el pensador francés afirma que hay una proposición que domina la filosofía, la cual es preciso imaginarla como un canto en griego; como un ritmo (Deleuze, 2008, pp. 484-485). Para Deleuze, la proposición $\ddot{\varepsilon} v \pi \alpha ́ v \tau \alpha$ es el clamor de los danzantes filósofos. En su despliegue, la filosofía asume un vínculo especial con el panenteísmo. "Lo uno todo Dios", o "lo uno todas las cosas Dios", es una fórmula que transporta hasta sus últimas consecuencias el origen repetitivo y diferencial del pensar.

Tras lo dicho, es factible afirmar que la problemática inmanentista tensa tanto el pensar deleuzeano como el pensar hegeliano. La proposición $\grave{\varepsilon} v \pi \alpha ́ v \tau \alpha$ induce una resonancia conceptual tan afín, que resulta imposible no distinguir en la escritura de Deleuze y Hegel la influencia del filósofo que con mayor soltura y tranquilidad aceptó el panenteísmo: Spinoza. Y es que problemas como el rasgo inmanente del deseo en cuanto que todo-uno-Dios, así como el de su expresión histórica, son parajes comunes en los textos de estos pensadores.

Ahora bien, en relación con la influencia que Spinoza ejerce sobre su pensar, habrá que apuntar inicialmente que Deleuze abraza de manera radical su ascendencia. En una de las últimas experimentaciones de su escritura doble con Félix Guattari, Deleuze escribe:

Spinoza es el vértigo de la inmanencia del que tantos filósofos tratan de escapar en vano. [...] Spinoza es el Cristo de los filósofos. [...] Spinoza, el devenir-filósofo infinito. Mostró, estableció, pensó el plano de inmanencia "mejor", es decir el más puro, el que no se entrega a lo trascedente ni inspira menos ilusiones, menos malos sentimientos y percepciones erróneas... (Deleuze \& Guattari, 2009b, pp. 52, 62).

Hegel es igualmente radical. Aunque en su ascendencia spinoziana podemos encontrar a la vez una de las mayores críticas hechas al filósofo neerlandés, ya que para el pensador alemán, ser seguidor de Spinoza es el comienzo esencial de todo pensar, esto a pesar de que en el pensar spinoziano haya demasiado Dios. En la Ética se puede leer:

Queda solo por indicar cuán útil es para la vida el conocimiento de esta doctrina, lo que advertimos fácilmente por lo que sigue, a saber: [...] En cuanto nos enseña que obramos por el solo mandato de Dios, y somos partícipes de la naturaleza divina, y ello tanto más cuanto más perfectas acciones llevamos a cabo, y cuanto más y más entendemos a Dios. Por consiguiente, esta doctrina, además de conferir al ánimo un completo sosiego, tiene también la ventaja de que nos enseña en qué consiste nuestra más alta felicidad o beatitud, a saber: en el solo conocimiento de Dios, por el cual somos inducidos a hacer tan solo aquello que el amor y el sentido del deber aconsejan (Spinoza, 2011, p. 202).

Apuntado lo anterior, en las siguientes líneas se prestará atención a un texto de Judith Butler titulado Sujetos del deseo. Reflexiones hegelianas en la Francia del siglo XX, en el cual la filósofa norteamericana asevera que la recepción francesa de Hegel en el siglo XX está reunida principalmente en torno a la lectura crítica del cuarto capítulo de la Fenomenología del espiritu: "La verdad de la certeza de sí mismo", apartado en el que Hegel lanza la siguiente sentencia: "la autoconciencia es deseo sin más" (Hegel, 2010, p. 247). Nos interesa hacer un recorrido sobre esta tesis doctoral, en consecuencia a que a pesar de que la autora afirma que su escrito es una obra de juventud y no tuvo en cuenta el grueso de escritos no traducidos, como fue la versión completa de la Introducción a la lectura de 
Hegel de Alexandre Kojève (Butler, 2012, pp. 9-21), en este se aprecia la problemática inmanente del deseo en Hegel y su recepción en Francia, tópico que Butler rastrea como propio del universo conceptual spinoziano y nos permite rastrear la manera como una determinada forma de hegelianismo fue apropiada por el espacio filosófico en el que Deleuze concreta su obra y desde el cual el pensador francés vislumbra los atisbos de trascendencia que se injertan en el teatro filosófico hegeliano.

Podemos comenzar por formular que la inmanencia del deseo abre con vehemencia todas las ventanas de un pensar abstracto ávido de seguridades. El deseo como ritmo diferencial del $\hat{\varepsilon} v \pi \alpha ́ v \tau \alpha$, aviva y exige el fuego propio de la creación. Para Butler, el deseo siempre fue presentado como lo otro de la filosofía; como aquello que debía ser amansado por la razón. De lo anterior no resulta extraño que la imagen de Spinoza vestido con su traje de revolucionario salte a la mente, el saber absoluto en Hegel sea concebido como delirio báquico y el pensar de Deleuze se presente como anarquía coronada. El concepto de deseo en el pensar, es la herida que desencadena el tercer género de conocimiento, el saber absoluto y el plan(o) de inmanencia en cuanto inconsciente productivo, todos ellos conceptos que se sublevan en contra del enemigo más temible: el pensamiento abstracto.

Pues bien, sobre las resonancias entre el pensar de Spinoza y Hegel, Butler escribe:

Según Spinoza y Hegel, el lugar metafísico del sujeto humano se define por medio de la racionalidad inmanente del deseo, puesto que el deseo es, al mismo tiempo, la lucha fundamental del sujeto humano y el modo mediante el cual ese sujeto redescubre y constituye su necesario lugar metafísico (Butler, 2012, p. 34).

Dejando por un instante el problema de la inmanencia del deseo en Spinoza, distingamos la manera como Butler vislumbra el deseo a partir del horizonte hegeliano. Butler afirma que en la Fenomenología

el deseo expresa la reflexividad de la conciencia, la necesidad de esa conciencia de convertirse en otra para sí a fin de conocerse. En cuanto deseo, la conciencia está fuera de sí, y al estar fuera de sí, la conciencia es autoconciencia (Butler, 2012, p. 37).

El deseo, entonces, se presenta como la búsqueda de identidad en lo que aparenta ser diferente. El sujeto no puede conocerse instantáneamente, este necesita ser mediado; precisa de la reflexividad.
El movimiento del deseo, como reflexividad de la conciencia es el viaje tortuoso en el que el sujeto descubre su espacio diferencial. Este descubrimiento lo conduce a desentramar momentos ontológicos, épocas de una aventura en la alteridad que tiene como principio el desvelamiento del reconocimiento (anerkennung). Se trata del desmembramiento báquico anunciado en el prólogo de la Fenomenología.

Deseo, reconocimiento y reflexividad plantean en el plano del pensamiento hegeliano el problema de la identidad. En el lugar absoluto de la identidad Hegel halla la satisfacción del deseo de reconocimiento en cuanto reflexividad; de ahí la afirmación por la negatividad. El deseo es la expresión misma de la negatividad toda vez que vincula el deseo humano con lo que él no es, razón por la cual la satisfacción misma del deseo es la transvaloración y afirmación de tal no del no-ser, de tal diferencia, en identidad. Tal satisfacción del deseo exige que la negatividad misma de éste, su nada, sea puesta como objeto de reflexividad, cuestión que lo conduce a reiniciar el círculo a través del saber, que ahora convertido en ciencia, se constituye como saber absoluto: la Lógica. Hegel afirma en la Fenomenología:

El ser está mediado absolutamente: es contenido substancial, que igualmente es inmediatamente propiedad del yo, tienen la cualidad del sí-mismo, o es el concepto. Con esto se concluye la Fenomenología del Espíritu. Lo que el espíritu se depara en ellas es el elemento del saber. En éste se expanden ahora los momento del espíritu en la forma de la simplicidad que sabe a su objeto como siendo ella misma. Esos momentos nos están ya disociados en la oposición de ser y saber, sino que permanecen en la simplicidad del saber, son lo verdadero en la forma de lo verdadero, y su diversidad es solo diversidad del contenido. Su movimiento, que se organiza en este elemento para resultar un todo, es la Lógica o filosofía especulativa (Hegel, 2010, pp. 95-97).

Podemos intuir, entonces, el motivo por el que para Hegel, si bien ser seguidor de Spinoza es el comienzo esencial de todo pensar, en el pensar spinoziano hay demasiado Dios. Para Hegel resulta indispensable destacar los momentos de la reflexividad del sujeto (las épocas); preguntarse cómo se llega al sistema. Butler nos afirma:

La metafísica de Spinoza adopta como su punto de partida la perspectiva del sistema ya completado, pero la Fenomenología de Hegel plantea la pregunta acerca de cómo se conoce ese sistema y de qué modo el sujeto cognoscente llega a conocerse como parte de ese sistema" (Butler, 2012, p. 44). 
Así, para Butler en la Fenomenología hay una reorientación antropocéntrica del monismo de Spinoza que conduce al pensamiento hegeliano a necesitar la negatividad como principio mismo de la autorrealización de un sujeto dispuesto en sendas históricas, las cuales lo empujan una y otra vez a perder y ganar su identidad para realizarse en sentido pleno. En el prólogo de la Fenomenología podemos leer:

La substancia viviente es, además, el ser que es en verdad sujeto, o lo que viene a significar lo mismo, que solo es en verdad en efecto en la medida en que ella sea el movimiento del ponerse a sí misma, o la mediación consigo misma del llegar a serse otra. En cuanto sujeto, ella es la pura negatividad simple, y precisamente por eso, es la escisión de lo simple, o la duplicación que contrapone, la cual, a su vez, es la negación de esta diversidad indiferente y de su contrario; solo esta igualdad que se restaura o la reflexión en el ser -otro hacia dentro de sí mismo, no una unidad originaria como tal, o inmediata como tal- es lo verdadero. Lo verdadero es el devenir de sí mismo, el círculo que presupone su final como su meta y lo tiene en el comienzo, y que solo es efectivamente real por llevarse a cabo y por su final.

Bien puede enunciarse, entonces, la vida de Dios y el conocimiento divino como un jugar del amor consigo mismo; esta idea se degrada hasta lo edificante, e incluso lo desabrido, cuando faltan en ella la seriedad, el dolor, la paciencia y el trabajo de lo negativo (Hegel, 2010, p. 73).

Para Hegel, a Spinoza le hizo falta el trabajo de lo negativo, su paciencia y dolor. En sus Lecciones de historia de la filosofia Hegel subraya: "este momento autoconsciente negativo, el movimiento del saber [...] está ausente en la filosofía de Spinoza [...] la negación solo está presente en cuanto Nada [...] no encontramos su movimiento, su Devenir y Ser" (Butler, 2012, p. 41).

Hegel insta a abrir las heridas. A desmembrar las identidades. Ese es el trabajo de lo negativo. En la Fenomenología el deseo busca su esclarecimiento, su transparencia, su expresión inmanente. Y para lograr tal, le resulta imperante conducir la reflexividad en las distintas épocas o momentos que constituyen la experiencia de la conciencia.

Afirmado lo anterior, quisiéramos centrar ahora la atención en el concepto de fuerza dispuesto en la Fenomenología, ya que tal noción es la bisagra que permite atender los rumores de ese ritmo inmanente bajo el cual piensan Spinoza, Hegel y Deleuze: la cadencia del $\tilde{\varepsilon} v \pi \alpha ́ v \tau \alpha$.

Butler afirma que es posible encontrar en el concepto de fuerza la reformulación hegeliana del conatus de Spinoza. Para Butler, la fuerza se precisa como entre. En la noción de fuerza se articula un movimiento constante del interior y el exterior, como un vaivén expresivo.

La fuerza es aquello que impulsa a una realidad interior a asumir una forma determinada, pero también es aquello que frustra la absorción de esa realidad interior en una forma determinada. [...] La fuerza mantiene una tensión entre lo que aparece y lo que no aparece (Butler, 2012, p. 61).

Así, resulta imposible no percibir la resonancia entre el interior y el exterior de la fuerza (lo solicitante y lo solicitado) con los conceptos de naturaleza naturante y naturaleza naturada en Spinoza. Conceptos que impiden a toda costa caer en las redes del pensamiento abstracto, el cual, asumido desde la Ética no es otro que el pensamiento servil. En la Ética, Spinoza apunta:

Por naturaleza naturante debemos entender lo que es en sí y se concibe por sí, o sea, los atributos de la sustancia que expresan una esencia eterna e infinita, estos es [...] Dios, en cuanto considerado como causa libre. Por Naturaleza naturada, en cambio, entiendo todo aquello que se sigue de la necesidad de la naturaleza de Dios, o sea, de cada uno de los atributos de Dios, en cuanto considerados como cosas que son en Dios, y que sin Dios no pueden ser ni concebirse (Spinoza, 2011, p. 96).

El concepto de fuerza, como aquello que frustra la absorción de esa realidad interior en una forma determinada, evita que se propicie la distinción de dos, en lo que solo es uno. En términos de Spinoza, evita que los hombres enjuicien lo vivo bajo formas ideales. Spinoza (2011), nos dice:

Pero cuando los hombres empezaron a formar ideas universales, y a representarse modelos ideales de casas, edificios, torres, etc., así como a preferir unos modelos a otros, resultó que cada cual llamó "perfecto" a lo que le parecía acomodarse a la idea universal que se había formado de las cosas de la misma clase. [...] Los hombres se han habituado a llamar perfectas o imperfectas a las cosas de la naturaleza, más en virtud de un prejuicio que por verdadero conocimiento de ellas (pp. 308-309).

Hegel, afirmando la doble cara de la inmanencia, describe el movimiento inmanente, denominado desde su horizonte conceptual como fuerza, de la siguiente forma:

Uno de sus momentos, a saber, el movimiento en cuanto expansión en su ser de las materias que se sostienen por sí mismas, es su manifestación exterior; pero, en cuanto que es el haber-desaparecido éstas, es la fuerza hecha retroceder hacia dentro de sí desde su manifestación hacia el exterior, o la fuerza propiamente dicha. Mas, primero, la fuerza hecha retroceder hacia dentro de sí tiene que manifestarse exteriormente, y luego, en segundo lugar, en la manifes- 
tación exterior, es fuerza dentro de sí misma tanto como es manifestación exterior en este ser-dentro-de-sí-misma. [...] [La] fuerza es lo universal incondicionado que es en sí mismo exactamente lo que es para otro; o bien, que tienen en ello mismo la diferencia -pues esta no es sino el ser para otro- (Hegel, 2010, pp. 205-206).

Para Hegel el juego de las fuerzas es el trasfondo de lo verdadero. El juego de fuerzas es lo negativo desarrollándose.

Tal juego de fuerzas es para Hegel una única ley, que paradójicamente es una pluralidad de leyes que coinciden en una. De nuevo el ritmo del $\grave{\varepsilon} v \pi \alpha ́ v \tau \alpha$. En el tercer capítulo de la Fenomenología leemos: "Así es que la ley está presente en un doble guisa: por un lado, como ley en la que están expresadas las diferencias como momentos autónomos; por otro, en la forma del simple haber regresando dentro de sî" (Hegel, 2010, p. 223).

El hacerse desigual lo igual y el hacerse igual lo desigual de dicha ley es lo que Hegel nombra como esencia simple de la vida, alma del mundo o sangre universal. De lo anterior, que Butler señale que en la Fenomenología "la autoconciencia promete conceptualizar la fuerza y la vida misma” (Butler, 2012, p. 63). La autoconciencia es un saber que es al mismo tiempo devenir: reflexividad. Es el viaje del deseo, de su dramatización. Butler afirma que se trata de una dialéctica del vitalismo en la cual la negación cancela, preserva y trasciende (aufhebung) las diferencias, manifestando así a la vida como la continua consolidación y disolución del sí mismo del sujeto.

Deseo devorador, deseo de reconocimiento y deseo del deseo de otro, son los momentos expresos hasta el capítulo cuarto de la Fenomenología. No obstante, solo a partir del movimiento de reflexividad adecuado al deseo como reconocimiento, se gesta el despliegue de la lucha y el drama del trabajo en el sujeto. Se trata de la expresión del juego de fuerzas del deseo como motor de la historia. La génesis de la dialéctica del amo y el esclavo.

Para una de las tesis que aquí se dejará bosquejada, es en la interpretación de este momento de la reflexividad de la conciencia que reside una de las mayores críticas al pensamiento hegeliano hecha por Deleuze. No obstante, antes de sumergirnos en tal calado crítico, se quisiera efectuar, de la mano de Kojève, un alzado mínimo sobre los momentos de la ciencia de la experiencia hegeliana, esto simplemente para tener en mente algunos de los personajes conceptuales emanados del motor negativo de la historia y con ello vislumbrar por qué el teatro filosófico hegeliano termina siendo para Deleuze un teatro de epifenómenos, es decir, un teatro de la representación.

\section{La crítica deleuzeana al teatro filosófico hegeliano. Los atisbos de trascendencia}

Para dar cuenta del teatro hegeliano, nos apoyaremos en los cursos que dieron pauta a la recepción y lectura francesa de Hegel en el siglo XX.

Dictados por Alexandre Kojève entre 1933 y 1939, los cursos Introducción a la lectura de Hegel, dictados en la École Pratique des Hautes Études y a los cuales asistieron pensadores como Bataille, Aron, Merleau-Ponty, Lacan e Hyppolite (a quien, por cierto, Deleuze dedica el texto Jean Hyppolite. Lógica y existencia, en el cual afirma que la lectura hegeliana de su maestro apela a una ontología del sentido y expresa: "después de este enriquecedor libro de Jean Hyppolite: ¿no sería posible hacer una ontología de la diferencia que no tuviese que elevarse hasta la contradicción?") (Deleuze, 2005, p. 25), encuentran como nódulo central el problema del deseo. A este respecto, el pensador ruso afirma:

$\mathrm{Al}$ contrario que el conocimiento que mantiene al hombre en una quietud pasiva, el Deseo lo vuelve in-quieto y lo empuja a la acción. La acción, al surgir del deseo, aspira a satisfacerlo, y solamente puede hacerlo mediante la "negación”, la destrucción o, como mínimo, la transformación del objeto deseado. [...] El hombre es la Acción negadora que transforma el Ser dado y que se transforma a sí mismo al transformarlo (Kojève, 2013, pp. 52, 211).

Ahora bien, Kojève pone el dedo en la llaga al afirmar que el deseo humano se diferencia del deseo animal en la medida en que el primero puede no versar exclusivamente sobre el deseo positivo, sino yacer sobre otro deseo. De ahí que para Kojève la historia humana sea la historia de los deseos deseados.

Se subraya lo anterior en consecuencia a que se quiere bosquejar todos esos puntos que constituirán la crítica deleuzeana al inmanentismo hegeliano. Tenemos, entonces, que hasta el momento los atisbos de trascendencia que se asoman en la filosofía inmanentista hegeliana comienzan cuando: 1. al deseo, en su plasticidad se le impone la estructura de la carencia, lo cual da pie a la lectura de la historia universal -la lucha entre el amo y el esclavocomo una historia de deseos reactivos, entusiasmados por la privación; y 2. cuando se diferencia el deseo animal, del deseo humano, instaurando con ello una jerarquía en la inmanencia.

Así pues, el deseo devorador, propio de un deseo animal de poseer lo no-yo (lo meramente cósico), el deseo de reconocimiento, motor de la historia, esto al propiciar la 
dialéctica entre la lucha y el trabajo, y el deseo del deseo de otro como satisfacción del deseo mismo, se presentan como una historia circular, en la que a través de la experiencia agónica de los momentos de la conciencia, se propicia el advenimiento del sabio y con él, la aceptación si más de la muerte del hombre. Kojève (2013) escribe:

La desaparición del hombre al final de la historia no es, así pues, una catástrofe cósmica: el mundo natural seguirá siendo lo que es para siempre. Y esto tampoco es una catástrofe biológica: el hombre seguirá vivo como animal que está en armonía con la naturaleza o el ser dado. Lo que desaparecería es el hombre propiamente dicho, es decir, la acción negadora de lo dado y el error, o, en general, el sujeto opuesto al objeto. En realidad, el final del tiempo humano o de la historia, es decir, la aniquilación definitiva del hombre propiamente dicho o del individuo libre e histórico, significa simple y llanamente el cese de la acción en el sentido fuerte del término. Lo cual quiere decir en términos prácticos: la desaparición de las guerras y de las revoluciones sangrientas. Y también la desaparición de la filosofía; pues si el hombre mismo ya no cambia esencialmente, ya no hay razón para cambiar los principios (verdaderos) que están en la base de su conocimiento del mundo y de sí mismo. Pero todo lo demás podrá mantenerse indefinidamente: el arte, el amor, el juego, etc.; en pocas palabras, todo cuando hace al hombre feliz (p. 489).

Sobre las lecturas dadas al sistema hegeliano como totalidad, como cierre y fin de la filosofía, y como visión del fin de la historia al propiciarse la satisfacción del deseo, hay bibliografía abundante. Por el momento, lo que se requería era el pretexto para, una vez bosquejados los escenarios de la Fenomenología, desplegar los personajes conceptuales que dramatizan la ciencia de la experiencia de la conciencia.

Tenemos, pues, que a partir de los escenarios del deseo devorador, el deseo de reconocimiento y el deseo del deseo de otro, Hegel irá construyendo personajes conceptuales que encarnaran su gran drama.

Hacer un resumen de la Fenomenología no es la intención de este líneas, por lo que en lo que sigue solo iremos llamando, como si se tratara de los créditos del final de una obra de teatro, a los personajes conceptuales.

En primer lugar, llamamos a los personajes del primer acto. Así, la inaugural figura en pisar las tablas es el hombre de la pura sensación, el hombre ingenuo, aquel que Hegel describe en el apartado de la certeza sensorial. Le sigue el hombre de la percepción; ese que puede decir por primera vez "yo". Posteriormente, está el hombre que se da cuenta de su necesidad de reconocimiento. Para Hegel, será el hombre que inicia el movimiento histórico.

Con el hombre del reconocimiento surge la dialéctica del amo y del esclavo y tras él, la experiencia de la conciencia servil. Conciencia que, causalmente, precisa de tres personajes conceptuales más: el esclavo estoico (aquel que ante lo real se retira exclusivamente al pensamiento para ganar una libertada abstracta); el esclavo escéptico (que presupone una liberación ilusoria y que por ende niega lo dado), y el esclavo de la conciencia desgraciada (que sin saberlo desarma la trascendentalidad afirmándola).

Una vez superada la experiencia de la conciencia servil se presenta en escena el hombre de razón. Dicho hombre soporta al mundo; ya no huye de él. El hombre de la razón irá adquiriendo diferentes máscaras conforme hace su monólogo: el hombre de la razón abstracta; el hombre de la república de las letras; el hombre de tierno corazón y el hombre que examina leyes, serán algunas de ellas. Todos son personajes que se baten en un duelo abstracto entre lo universal y lo particular, así como en la dialéctica de la lucha y el trabajo, y del amo y el esclavo.

Tras la salida del hombre de razón, Hegel instaura un receso para anunciar en este drama un segundo acto dispuesto sobre dos escenarios: el escenario del espíritu y el escenario de la religión. En tales escenarios, Hegel hace hincapié en que el hombre real es un ser social, político e histórico. De lo anterior, que a partir de que el telón sube en el segundo acto, en el fondo comiencen a trazarse horizontes propios de la historia universal.

De este modo, en el escenario del espíritu, en la disposición de un horizonte griego, subirá a escena el hombre ético para, posteriormente, en la disposición de un horizonte romano, se presente el hombre jurídico. El siguiente personaje en escena es el hombre cristiano, un personaje extrańado de sí. Después de la exposición de la conciencia desgraciada, el horizonte cambia, el mundo feudal aparece en su contradicción con el mundo burgués. Paralelamente, en tal horizonte el hombre absoluto da su última sentencia en el mismo instante en que el hombre de la propaganda revolucionaria proclama los edictos de la futura ciencia atea. Aparece, entonces, el hombre de la Ilustración. Dicho hombre conducirá hasta sus últimas consecuencias la necesidad del reconocimiento, lo cual le provocará dibujar en su horizonte el terror. Una vez caído el horizonte del terror, Hegel nos presentará al hombre moral, un hombre de alma bella que todavía no afirma su individualidad en consecuencia a que aún no realiza en lo real la síntesis de lo particular y lo universal. 
Por otro lado, en el escenario conjunto, a saber, el escenario de la religión, sale a escena primeramente el hombre de la religión natural y con él saldrán tres personajes enmascarados: uno con esencia luminosa, otro con un tótem y un último con técnica. El hombre de la esencia luminosa, el hombre totémico y el maestro artesano, son todos ellos movimientos propios de los momentos universales del espíritu de la religión.

Tras el hombre de la religión natural sale a escena el hombre de la religión-arte. Hombre que en un primer momento ejecuta grandes esculturas abstractas con las que experimentan el hiato entre lo universal y lo particular. En un segundo momento, genera obra de arte viva por medio del lenguaje y por último, hace la obra de arte espiritual trágica y cómica.

El último hombre de esta escena es el hombre que anuncia que Dios ha muerto. Este hombre proclama el dolor de parto del espíritu absoluto y con este la muerte de lo abstracto.

El tercer y último acto está condicionado por la aparición en escena del personaje conceptual del sabio; es el salto que da cuenta del fin de la filosofía. Sobre ello, Kojève afirma que: 1. la sabiduría es el arte de responder todas las preguntas por medio de un saber enciclopédico, mientras que la filosofía es el arte de plantear las preguntas; 2. la sabiduría es el hombre satisfecho con lo que él es, mientras que el filósofo solo es aquel que tiene conciencia de su estado de insatisfacción, y 3. el sabio es modelo para sí mismo y para los demás, mientras que el filósofo es un modelo negativo, ya que es aquel que quiere llegar a ser sabio por medio de una pedagogía dialéctica. El sabio es el ciudadano del Estado universal; el que logra satisfacer el deseo. El sabio propicia la realización del concepto.

Vista en su generalidad la trama de la obra hegeliana, podemos continuar enumerando los atisbos de trascendencia que se asoman en la filosofía inmanentista hegeliana, esto con el fin de vislumbrar la critica deleuzeana al pensamiento inmanente de Hegel.

Tenemos, entonces, que el primer atisbo de trascendencia es la estructura de la carencia inserta en la concepción de deseo. El segundo atisbo responde a la instauración de una jerarquía en la inmanencia. El tercer atisbo (el cual ha causado uno de los mayores revuelos) es el fin de la historia y con este el fin de la filosofía, todo ello asegurado por una telos. El cuarto atisbo es el hecho de haber subsumido los personajes causalmente. El quinto y último atisbo tiene que ver con el planteamiento de los problemas y las respuestas dadas a tales instancias.
Así, después de apuntar los atisbos de trascendencia y mostrar superficialmente los personajes conceptuales hegelianos, cabría afirmar que para Deleuze el teatro hegeliano no es más que un teatro vacío, una dramatización nihilista en la que el deseo expresado es un deseo patológico.

Deleuze no vislumbra a Hegel como fundador del teatro por venir. En palabras de Deleuze: Hegel "representa conceptos en lugar de dramatizar ideas: hace un falso teatro, un falso drama, un falso movimiento" (Deleuze, 2006, p. 34).

En lo que sigue y dejando de lado los atisbos de trascendencia enumerados, se quisiera plantear la crítica de Deleuze a Hegel enfocándonos específicamente en la lectura que hacen sobre Spinoza y el deseo.

\section{El limitado spinozismo hegeliano}

Deleuze sospecha que en la obra del pensador alemán hay un limitado spinozismo. Al respecto, Deleuze (2009) anota:

Por ejemplo, Goethe, o incluso Hegel, bajo determinados aspectos, han podido pasar por spinozistas. Pero no lo son realmente, porque siguieron vinculando el plan a la organización de una Forma y a la formación de un Sujeto. Los spinozistas son más bien Hölderlin, Kleist, Nietzsche, por que piensan en términos de velocidades y de lentitudes, catatonías petrificadas y movimientos acelerados, elementos no formados, afectos no subjetivados (p. 156).

Así, ante al reproche de Hegel a Spinoza de no haber realizado el trabajo de lo negativo, Deleuze asevera:

En el reproche que Hegel hará a Spinoza, haber ignorado lo negativo y su potencia, reside la gloria y la inocencia de Spinoza, su más propio descubrimiento. En un mundo roído por lo negativo, él tiene suficiente confianza en la vida, en la potencia de la vida, como para controvertir la muerte, el apetito asesino de los hombres, las reglas del bien y el mal, de lo justo y de lo injusto. Suficiente confianza en la vida como para denunciar todos los fantasmas de lo negativo (p. 22).

A partir de la lectura deleuzeana, Hegel vive un mundo roído por lo negativo; es decir, en un mundo en el que el deseo se desdobla y se descifra como carencia causal. Frente a la necesidad de negar lo vivo, el presente, por medio de la acción, Deleuze y Spinoza afirman a la vida misma como creación activa afirmativa. Mientras que Hegel apunta:

La muerte [...], es lo más pavoroso y mantener aferrado lo muerto es lo que requiere una fuerza suprema. La belleza que no tiene fuerza odia al entendimiento, porque éste le exige 
que haga lo que ella no es capaz de hacer. Pero la vida del espíritu no es la vida que se asusta de la muerte y se preserva pura de la devastación, sino lo que la soporta y se mantienen en ella (Hegel, 2010, p. 91).

Spinoza señala: "Un hombre libre en nada piensa menos que en la muerte, y su sabiduría no es una meditación de la muerte, sino de la vida" (Spinoza, 2011, p. 389).

La acción se afirma en el presente, con lo cual se denuncia lo negativo como epifenómeno. Spinoza afirma: "Por realidad entiendo lo mismo que por perfección" (Spinoza, 2011, p. 123).

Para Deleuze, Spinoza piensa en velocidades y lentitudes. Sus tres géneros del conocimiento no son momentos causales insertos en una teleología. Son velocidades y lentitudes contingentes. Ontología del sentido atravesada por el juego de fuerzas. Junto a la pluma de Guattari, Deleuze declara:

Quien sabía plenamente que la inmanencia solo pertenecía a sí misma, y que por lo tanto era un plano recorrido por los movimientos del infinito, rebosante de ordenadas intensivas, era Spinoza. Por eso es el príncipe de los filósofos. Tal vez el único que no pactó con la trascendencia, que le dio caza por doquier. Hizo el movimiento del infinito, y confirió al pensamiento velocidades infinitas en el tercer tipo de conocimiento, en el último libro de la Ética. Alcanzó en él velocidades inauditas, atajos tan fulminantes que ya solo cabe hablar de música, de tornado, de vientos, y de cuerdas. Encontró la única libertad en la inmanencia. Llevó a buen fin la filosofía, porque cumplió su supuesto prefilosófico (Deleuze \& Guattari, 2009b, pp. 51-52).

Deleuze vislumbra en Spinoza el juego inmanentista del $\grave{\varepsilon} v \pi \alpha ́ v \tau \alpha$. Para Deleuze, solo el filósofo que gustaba ver la lucha entre arañas afirmó con mayor precisión el caosmosis propio de la inmanencia, propiciando con ello que la historia universal no sea otra más que la historia universal de la contingencia, del juego azaroso de fuerzas.

Desde esta óptica, parece como si Hegel, bajo un spinozismo limitado, se abocara a pensar el juego de fuerzas en la historia exclusivamente desde el ámbito de la actualización, cuestión que lo induce a vislumbrar el deseo como algo que debe ser satisfecho y por lo mismo, como carencia.

De este modo, una de las tesis centrales del Anti-Edipo puede ser leída como una afirmación que teniendo resonancias con la Fenomenología va más allá que ésta en consecuencia a que, teniendo como trasfondo un spinozismo radical, no se afianza en la mera actualización.
Es por completo cierto que lo social y lo metafísico llegan al mismo tiempo, de acuerdo con los sentidos simultáneos de proceso, como proceso histórico de producción social y proceso metafísico de producción deseante. [...] No hay más que lo social y lo metafísico (Deleuze \& Guattari, 2009a, p. 369).

De la misma forma que para Hegel el deseo y la producción social constituyen el proceso de devenir, para Deleuze y Guattari no hay más que lo social y lo metafísico, y no obstante, a pesar de que esta fórmula de inmanencia alumbra el pensar de estos filósofos, hay una mínima desunión que provoca un alejamiento tajante.

Para Deleuze-Guattari, entre el proceso histórico de producción social y el proceso metafísico de producción deseante, se produce un agencement. Tal agencement -a diferencia del movimiento histórico dialéctico del deseo dispuesto en la Fenomenología, donde la negación cancela, preserva y trasciende (afhebung) las diferencias- se produce en un espacio-tiempo de velocidades infinitas, de tal manera que su expresión -su exterioridad- solo puede ser contingente, por lo que la causalidad, en cuanto cancelación, preservación y trascendencia, únicamente puede ser percibida como un epifenómeno propio de la cara de la actualización; en términos de Spinoza: de la natura naturada.

Frente al teatro de la representación hegeliano dispuesto en la Fenomenología, Deleuze y Guattari apelarán por una embriología del deseo; el deseo como un huevo. Intensidad cero que "no es lo contrario de las potencias intensivas, [sino] la materia intensiva pura” (Deleuze, 2010, p. 91).

Los conceptos de lo virtual, de deseo, de intensidad $=0$, de huevo, de cuerpo sin órganos, permiten afirman que el plan(o) del deseo no es un teatro de la representación. Los momentos de la Fenomenología del espíritu son epifenómenos del deseo. Son la expresión vital de este y, no obstante, su dramatización se queda en mera representación.

En el teatro de la representación, Hegel parece necesitar preguntarse por el qué y el por qué de la historia, mientras que en el teatro de la crueldad Deleuze y Guattari solo se preguntan por el quién y el cómo (funciona), enciclopedia frente a pedagogía, sabio frente a filósofo.

$\mathrm{Al}$ preguntarse por el cómo, Deleuze y Guattari afirman una pragmática; no hay interpretación. El deseo se presenta como proceso inmanente. Deleuze y Guattari aseveran que "la producción como proceso desborda todas las categorías ideales y forma un ciclo que remite al deseo en tanto que principio inmanente" (Deleuze $\&$ 
Guattari, 2009a, p. 14). El deseo como repetitiva expresión diferencial.

Por último, y como cierre de este indagatoria, para Deleuze el hecho de que en Spinoza haya demasiado Dios no representa problema alguno. Como lo señala Heffese: "Ese Dios del que tanto se habla en filosofía es resignificado en tanto medio de creación de conceptos" (2016). En la clase del 25 de noviembre de 1980, Deleuze comenta:

Del mismo modo que yo decía que Dios y Cristo fueron para la pintura una extraordinaria ocasión parar liberar las líneas, los colores y los movimientos de las coacciones de la semejanza, Dios y el tema de Dios fue para la filosofía la ocasión irremplazable para liberar aquello que es el objeto de creación de la filosofía, es decir los conceptos, de las coacciones que les hubiera impuesto el hecho de ser la simple representación de las cosas. Es al nivel de Dios que el concepto es liberado, porque ya no tiene por tarea representar algo.

He aquí que lo que Spinoza va a llamar "Dios" en el libro primero de la Ética va a ser la cosa más extraña del mundo. Va a ser el concepto en tanto que reúne el conjunto de todas sus posibilidades. A través del concepto filosófico de Dios se hace -y no podría hacerse más que ese nivel- la más extraña creación de la filosofía como sistema de conceptos (Deleuze, 2008, pp. 21-23).

Para Deleuze el Dios de Spinoza es el campo problemático que abre la posibilidad de la emancipación máxima. El Dios de Spinoza es el plan(o) de inmanencia en el que todo está permitido. En Dios, las velocidades y lentitudes de los flujos rompen con la estratificación del pensamiento dispuesto sobre la oposición, la semejanza, la identidad y la analogía. En Dios el concepto es liberado en el sentido en que ya no representa nada, no está dispuesto sobre un modelo de reconocimiento. El Dios de Spinoza es otro ritmo filosófico del clamor gestado por la cadencia de la sentencia $\ddot{\varepsilon} v \pi \alpha ́ v \tau \alpha$.

\section{Referencias}

Butler, J. (2012). Sujetos del deseo. Reflexiones hegelianas en la Francia del siglo XX. Buenos Aires: Amorrortu.

Deleuze, G. (2010) Derrames. Entre el capitalismo y la esquizofrenia. Buenos Aires: Cactus.

Deleuze, G. (2006) Diferencia y repetición. Buenos Aires: Amorrortu.

Deleuze, G. (2008) En medio de Spinoza. Buenos Aires: Cactus.

Deleuze, G. (2005) La isla desierta y otros textos. Textos y entrevistas (1953-1974). Valencia: Pre-textos.

Deleuze, G. (2009) Spinoza filosofia práctica. Barcelona: Tusquets.

Deleuze, G. \& Guattari F. (2009a). El Anti Edipo. Capitalismo y esquizofrenia. Buenos Aires: Paidós.

Deleuze, G. \& Guattari F. (2009b) ¿Qué es la filosofía? México: Anagrama.

D'Hondt, J. (2013) Hegel. México: Tusquets.

Heffesse, S. (2016) Complicatio-explicatio: Nicolás de Cusa y el camino hacia un Spinoza deleuziano. Rev. Guillermo de Ockham, 14(2), 53-63.

Hegel, G. W. F. (2010) Fenomenología del espiritu. Madrid: Abada.

Kojève, A. (2013) Introducción a la lectura de Hegel. Madrid: Trotta.

Spinoza, B. (2011) Ética demostrada según el orden geométrico. Madrid: Alianza. 